\title{
A IMPORTÂNCIA DO SISTEMA ELETRÔNICO DE INFORMAÇÕES - SEI, COMO MECANISMO DE GESTÃO PARA OTIMIZAÇÃO DOS PROCESSOS NO DISTRITO SANITÁRIO ESPECIAL INDÍGENA MÉDIO PURUS
}

\section{ARTIGO ORIGINAL}

SANTOS, Ediminilto Silva dos ${ }^{1}$

MADURO, Márcia Ribeiro ${ }^{2}$

SANTOS, Andreza Siqueira dos ${ }^{3}$

LIMA, Orlem Pinheiro de ${ }^{4}$

ARAÚJO, Paulo César Diniz de ${ }^{5}$

SOUZA, Andréa Lanza Cordeiro de ${ }^{6}$

OLIVEIRA JÚNIOR, Nilson José de ${ }^{7}$

SANTOS, Ediminilto Silva dos. Et al. A importância do Sistema Eletrônico de Informações - SEI, como mecanismo de gestão para otimização dos processos no Distrito Sanitário Especial Indígena Médio Purus. Revista Científica Multidisciplinar Núcleo do Conhecimento. Ano 05, Ed. 12, Vol. 04, pp. 60-76.

\footnotetext{
${ }^{1}$ Especialista.

2 Doutora em Administração.

${ }^{3}$ Especialização em MBA Gestão de Recursos Humanos.

${ }^{4}$ Doutor em Engenharia de Produção.

${ }^{5}$ Doutor em Administração.

${ }^{6}$ Doutora em Biodiversidade e Biotecnologia na Amazônia.

${ }^{7}$ Mestre em Contabilidade e Controladoria.
} 
Dezembro de 2020. ISSN: 2448-0959, Link de acesso: https://www.nucleodoconhecimento.com.br/administracao/sistema-eletronico

\section{RESUMO}

Este artigo tem como ênfase a importância do Sistema Eletrônico de Informações SEI, que atua como mecanismo de gestão para otimização dos processos no Distrito Sanitário Especial Indígena Médio Purus. Neste contexto, busca-se responder qual a importância do SEl, como mecanismo de gestão, para otimização dos processos no Distrito Sanitário Especial Indígena Médio Rio Purus. A pesquisa justifica-se pela necessidade de avaliação do SEI como mecanismo de gestão, visto que é capaz de reduzir gastos com impressões e tornar mais célere a tramitação dos processos, tanto internamente como externamente. Tem-se, como objetivo central, avaliar a importância do SEI como mecanismo de gestão para otimização dos processos no Distrito Sanitário Especial Indígena Médio Rio Purus. Deste modo, os objetivos específicos visam: a) descrever como o SEI atua na gestão de processos administrativos; b) comparar o desenvolvimento das atividades de gestão por meio de processos físicos e por meio do SEl; c) avaliar quais aspectos do SEI foram alcançados com os propostos na implantação do programa. O trabalho foi desenvolvido a partir de uma pesquisa bibliográfica, de cunho descritivo, apoiando-se na abordagem quantitativa e qualitativa, e, assim, buscou-se explorar e explicar os principais impactos quanto ao uso de Sistemas Eletrônicos de Informações na gestão do Distrito Sanitário Especial Indígena Médio Rio Purus.

Palavras-chave: Sistema de Informação, Processo Eletrônico Nacional, SEl.

\section{INTRODUÇÃO}

O uso dos SI como ferramenta de gestão teve seus primórdios em meados da década de 70 , oriundo das transformações tecnológicas, sendo inserido, primeiramente, nas organizações privadas, sendo que a implantação ocorria de forma menos burocrática e mais célere. Na Administração Pública, os tribunais judiciários foram os pioneiros na implantação dos sistemas eletrônicos de informação, pois buscava-se mecanismos 
para tornar mais ágil o fluxo de informações nos processos, tanto ao público externo como ao público interno, e, ao mesmo tempo, buscava-se reduzir os altos custos com insumos necessários para a execução das atividades finalísticas das repartições, permitindo maior flexibilidade e transparência na tomada de decisões. Diante da otimização do tempo e agilidade no fluxo de informações, a Administração Pública busca aprimorar e acompanhar as inovações tecnológicas.

Esse movimento ensejou-se com o bureau de serviços e, hoje, conta com o uso de Data Centers e de Computação em Nuvem, com vistas a solucionar problemas relacionados à tecnologia da informação, com infraestrutura e plataforma de serviços e, também, soluciona-se problemas associados à falta de espaços físicos para arquivamento de milhares de documentos, contribuindo, então, para a melhora da comunicação entre os órgãos, ampliando a eficiência do serviço. Desse modo, o Processo Eletrônico Nacional (PEN) surge como uma necessidade e é uma ação conjunta de diversos órgãos, de diferentes esferas públicas, cujo propósito é o de desenvolver mecanismos de atendimento público por meios eletrônicos, capazes de tornar célere, reduzir custos, permitir o fácil acesso à transparência e preza-se pelo bem-estar do usuário.

Neste cenário, considerando a amplitude da Gestão Pública e sua funcionalidade, a pesquisa volta-se à organização dos serviços de saúde destinados aos povos indígenas situados na jurisdição do Distrito Sanitário Especial Indígena Médio Rio Purus, que é uma unidade gestora autônoma do SasiSUS, que possui um modelo organizacional, cuja finalidade é promover a atenção básica de saúde aos índios aldeados, articulada com o SUS (BRASIL, 2001). Com o intuito de melhorar a gestão e agilizar os processos no âmbito das comunidades indígenas, a partir de $1^{0}$ de outubro de 2017, entrou em funcionamento o SEI, no Distrito Sanitário Especial Indígena Médio Rio Purus, tornando digitais, a partir da implantação do sistema, todos os procedimentos administrativos, que passaram a ser criados em plataformas eletrônicas.

Assim, contribui-se para com a redução expressiva no consumo de materiais de expediente, maior agilidade no envio dos processos licitatórios para a assessoria 
jurídica CJU/AM, bem como o envio e recebimento de documentos para a Secretaria Especial de Saúde Indígena - SESAI, a qual o órgão é subordinado, possibilitando, ainda, maior efetividade na transparência de dados junto aos órgãos de controle. Diante dessa realidade, busca-se refletir sobre qual a importância do SEI como mecanismo de gestão para otimização dos processos no Distrito Sanitário Especial Indígena Médio Rio Purus. A princípio, é importante destacar que este estudo justificase pela necessidade de avaliação do SEI no âmbito da instituição, considerando seus impactos na redução dos custos e celeridade na tramitação dos processos, tanto internamente como externamente, pois o envio dos arquivos é por meio eletrônico, permitindo, ao gestor público, o acesso em qualquer lugar, por meio de computadores, tabletes ou smartphones, eliminando, desta forma, o grandes volume de processos físicos que, com o passar dos anos, desgastam-se.

Desta forma, este artigo tem, como objetivo central, avaliar a importância do SEI como mecanismo de gestão para otimização dos processos no Distrito Sanitário Especial Indígena Médio Rio Purus, e, como objetivos específicos, visa: a) descrever a atuação do SEI na gestão de processos administrativos; b) comparar o desenvolvimento das atividades de gestão por meio de processos físicos e através do SEl; c) avaliar quais aspectos SEI foram alcançados com os propostos na implantação do programa. O trabalho foi desenvolvido por meio de uma pesquisa bibliográfica, de cunho descritivo, apoiando-se na abordagem quantitativa e qualitativa, buscando-se explorar e explicar os principais impactos quanto ao uso de Sistemas Eletrônicos de Informações na gestão do Distrito Sanitário Especial Indígena Médio Rio Purus.

O conteúdo apresentado neste artigo tem a seguinte estrutura: resumo, introdução ao tema abordado, revisão da literatura, resultados e discussões quanto aos impactos gerados pelo SEI na gestão do Distrito Sanitário Especial Indígena Médio Rio Purus. Por fim, finaliza com as reflexões finais e referências bibliográficas. 


\section{REVISÃO DE LITERATURA}

\subsection{SISTEMA DE INFORMAÇÃO E SISTEMA INFORMATIZADO DE INFORMAÇÕES}

O volume crescente de informações nos ambientes organizacionais tem impulsionado as instituições a implantar sistemas informatizados de informações, que, por sua vez, possibilitam o planejamento de ações, bem como facilitam os processos decisórios e a execução das ações planejadas. Com o intuito de esclarecer melhor os conceitos estudados, pode-se dizer que os termos informação e SI estão sempre associados, já que ambos admitem características do contexto ou do conjunto alocado, além de serem uma parte indispensável de um composto, uma vez que a informação é responsável pelo funcionamento organizado do sistema (JANNUZZI; TÁLAMO, 2004). As informações, por sua vez, perpassam por três estágios primordiais: o recebimento de dados, o segundo refere-se ao processo de interpretação e análise e, por fim, há o processamento de dados, também chamado de informação válida.

Nos processos decisórios organizacionais, os resultados positivos dependem da qualidade e confiabilidade a partir das quais a informação foi processada, assim, se a informação não tiver qualidade, os resultados não serão satisfatórios (CAPELLÃO, 2008). Nesse sentido, Jannuzzi e Tálamo (2004) consideram que, na etapa preliminar do período informacional, informação potencial (dados), há, no espaço privado, a figura do emissor, por conseguinte, o segundo ciclo o do fluxo, que se transforma no espaço público da transmissão, estabelecendo uma relação contínua entre o público e o privado, integrando as diferentes formas de tratamento e os diferentes atores. Por sua vez, a utilização de SI requer maior foco da organização em estratégias de tecnologias da informação, nos processos produtivos da instituição, uma vez que, "um sistema de informação é uma solução organizacional e administrativa, baseada na tecnologia de informação, para um desafio imposto pelo ambiente" (LAUDON; LAUDON, 2001). 
Os SI são considerados mecanismos para alcance de resultados das mais variadas adversidades encontradas em um ambiente de trabalho, como a ociosidade pela falta de comunicação entre os departamentos da empresa, ausência de padronização no fluxograma das produções e a insuficiência de informações verídicas e de qualidade. Conceitua-se, ainda, como um agregado de informações que permite-se realizar e gerenciar determinadas tarefas de forma automatizada (softwares, websites e etc.) ou manual, no qual abrange as pessoas, máquinas e métodos. Ao contrário do que se pensa, um SI nem sempre está ligado a área de informática, pois sua definição está relacionada ao método utilizado na transmissão e acolhimento de dados (CASSARO, 2010). Em termos gerais, os SI podem possuir processos pré-definidos, ou seja, normatiza-se os parâmetros na execução das atividades e transferência de dados, a serem classificados como meios formais.

Por outro lado, os SI também se caracterizam por sua natureza informal, uma vez que existem meios de comunicação além das determinadas nas organizações públicas e privadas, como troca de correspondência eletrônica (TURBAN et al, 2004). Os sistemas informatizados de informações são programas para computadores e dispositivos móveis capazes de gerenciar e organizar as atividades internas processuais da empresa e surgem como uma necessidade das organizações, seja ela pública ou privada, de se adequarem a chamada "era da informação" e melhorar o processos decisórios com base em informações atuais e fidedignas. A utilização de sistemas informatizados gerenciais resulta em benefícios como: aumento da transparência nas atividades realizadas, reduz os trâmites burocráticos, torna o negócio mais competitivo e eficiente, além, é claro, de reduzir os danos causados ao meio ambiente, tendo em vista que os processos são elaborados em plataforma eletrônica e, consequentemente, há a diminuição de contas com materiais (LAUDON, 1999).

Compreende como sistemas informatizados aqueles que integram seis componentes básicos: os computadores (hardware), os programas (software), os seres humanos (pessoas), arquivos de dados, redes e procedimentos. Convém salientar que os referidos sistemas só terão eficácia se cada componente funcionar corretamente e se 
forem executados em conjunto (O'BRIEN, 2002). Para qualquer organização que almeje competitividade no mercado atual, a utilização da informação como mecanismo de gestão infuencia, proporcionalmente, na capacidade de êxito nos objetivos propostos, bem como no sucesso do negócio. Assim, nos ambientes organizacionais, os SI estão atrelados, principalmente, ao uso dos sistemas informatizados, pois estes são primordiais aos processos administrativos das organizações (JANNUZZI et al, 2014).

A escolha de um SI adequado é uma função essencial de um gestor em sua organização, entretanto, essa não é uma tarefa fácil, tendo em vista os inúmeros tipos de sistema de informações encontrados e que, por muita das vezes, acabam sendo repetitivos, redundantes e extremamente subjetivos em seus conceitos (JANNUZZI et al, 2014).

\subsection{PROCESSO ELETRÔNICO NACIONAL (PEN)}

O processo eletrônico nacional teve início com a sanção da Lei 11.419/2006, na qual fora instituída a informatização dos processos judiciais por meio dos quais os tribunais regionais buscavam tornar mais célere e eficazes os trâmites processuais, apresentando maiores índices de resolutividade. Após quase duas décadas da criação da Lei № 11.419/2006, os governos de diferentes entes da Administração pública deram início ao chamado Processo Eletrônico Nacional - PEN, que tem por objetivo principal o desenvolvimento de mecanismos de atendimento público por meio eletrônico, de modo que possa ser usado em qualquer órgão público dos diferentes entes federativos nas suas atividades diárias de atuação específica (BRASIL, 2016). O projeto piloto para a instituição do PEN foi iniciado após a assinatura de três termos de cooperação técnica, em 17 de junho de 2013, em acordos firmados pelo MPOG, a CVM, o Governo do Distrito Federal e a Embrapa.

Por conseguinte, o segundo acordo firmado pelo MPOG e a Receita Federal do Brasil resultou em uma maior referência-chave para o desenvolvimento do PEN, após ter sido constatado o enorme poder transformador que o programa traria. Por fim, o terceiro acordo foi firmado pelo MPOG e o TRF4, após consulta pública realizada nos 
meses de janeiro e fevereiro de 2013, para fins de aceite de soluções de eventuais detentores que pudessem disponibilizar o conhecimento em forma de cessão gratuita (BRASIL, op. cit.). O software apresentado pelo TRF4 destacou-se em relação aos demais, sobretudo pela celeridade na realização das atividades administrativas, diminuindo o tempo de resposta, bem como a organização dos fluxos de trabalho, deixando de lado o paradigma da utilização do papel e ganhando proporções gigantescas em agilidade, transparência e segurança. O sistema proposto pelo referido tribunal possibilitava a virtualização do processo de trabalho em âmbito administrativo e permitia a atuação de diversas unidades num mesmo processo, embora distantes fisicamente (BRASIL, 2016).

A criação do Processo Eletrônico Nacional resultou de um trabalho coordenado pela Secretaria Executiva do MPOG em colaboração com vários órgãos e entidades, tendo como fator motivador a necessidade de modernização tecnológica de acesso e recuperação da informação, preconizada pela Lei № 12.527/2011- Lei de acesso a informação. O PEN é composto por três grandes ações: O SEI (software cedido gratuitamente pelo TRF4 para Instituições públicas), o barramento de integração do SEI (infraestrutura centralizada que possibilita aos órgãos a transferência de documentos e processos administrativos de forma segura e confiável, independentemente da tecnologia adotada) e o protocolo integrado (mecanismo utilizado por diferente órgãos e entidades para registro e trâmite de diversos documentos, além de possibilitar à sociedade mais um canal de consulta acerca de processos e documentos) (BRASIL, 2016).

Em suma, a necessidade de desburocratização pela administração pública surge da enorme pressão popular, demandando-se que sejam adotados mecanismos no desenvolvimento das atividades administrativas por meio de serviços e políticas públicas, e, ainda, reitera-se a aplicação correta dos recursos públicos. Neste contexto, o PEN mostra-se eficiente e desburocratizador, tendo em vista os inúmeros registros de benefícios já alcançados, tornando o processo eletrônico altamente desejável (UCHOA; AMARAL, 2013). Uchoa e Amaral (2013, p. 5) ressaltam que a principal justificativa do PEN é: "disponibilizar um conjunto de ferramentas, 
metodologias e instrumentos normativos que possibilitem a utilização do processo eletrônico pelos governos federais, estaduais e municipais, ou ainda qualquer órgão ou entidade pública". A termos de exemplificação, a introdução do processo eletrônico sob gerência da Receita Federal do Brasil, segundo Uchôa e Amaral, (2013, p. 8):

[...] reduziu o trâmite dos processos em até $40 \%$, aumento de produtividade dos servidores; melhor atendimento ao cidadão; melhor transparência e gestão do conhecimento; redução de $2 / 3$ da quantidade de papel impresso e redução de $70 \%$ do espaço de armazenagem. Fatores importantíssimos que resultaram na economia de mais de 200 milhões de reais anuais, tendo, pois, a implementação da solução custado $10 \%$ (dez por centos) desse valor, trazendo um ótimo retorno custo - benefício, o que resultou como o $1^{\circ}$ lugar no $16^{\circ}$ Concurso Inovação na Gestão Pública Federal em 2013 [...] (UCHOA; AMARAL, 2013, p. 8).

A solução equalizada pelo processo eletrônico nacional beneficia centenas de órgãos, principalmente os da esfera municipal que nem sempre possuem aportes financeiros capazes de desenvolver sistemas tão eficientes e à custo baixo. Entretanto, ressaltase que tal medida só é possível em virtude da solução apresentada, uma vez que esta ser acessível abertamente e disponibilizada no Portal do Software Público Brasileiro garante o acesso à propriedade pública, apontando-se se há a inexistência de custos com licenciamento, bem como se há a autonomia em relação à evolução do produto (UCHOA; AMARAL, 2013).

\subsection{SISTEMA ELETRÔNICO DE INFORMAÇÕES - SEI NA GESTÃO DE PROCEDIMENTOS ADMINISTRATIVOS}

O SEl é uma plataforma digital que possui diversas funcionalidades, engloba inúmeros serviços e permite o desenvolvimento de processos e o envio e recebimento de documentos eletrônicos de maneira prática e fácil para os usuários. No SEI, os documentos institucionais são criados e tramitados entre as diferentes organizações, de forma eletrônica, o que reduz os custos com aquisição de papéis, materiais de expediente, serviço de correios e serviços de impressões (BRASIL, 2018). Dada à importância do SEI, as diferentes organizações da Administração Pública das três esferas de governo têm utilizado o SEI devido à facilidade de acesso, que permite o 
acesso remoto pelo usuário em qualquer lugar, seja no trânsito, em viagem ou até mesmo no aconchego do lar. Assim, pode-se desenvolver as atividades das quais está encarregado de forma mais prática. Por conseguinte, Brasil (op. cit., p. 8), define as principais especificidades e facilidades do SEI:

- Acesso Remoto: pode ser feito o acesso remoto, possibilitando que o usuário trabalhe à distância a partir de seus microcomputadores, notebooks e smartphones;

- Acesso de usuários externos: controla os acessos externos de usuários a documentos e processos;

- Controle de nível de acesso: controle na criação de documentos e processos restritos e sigilosos, permitindo o acesso somente às unidades que os criaram;

- Tramitação em múltiplas unidades: unidades distintas podem ser demandadas simultaneamente;

- Funcionalidades específicas: acompanhamento especial, inspeção administrativa, controle de prazos, base de conhecimento, tempo de processo, organização de processos em bloco, pesquisa em todo teor, assinatura em bloco, estatísticas da unidade, ouvidoria e etc.;

- Sistema intuitivo: facilidade de adaptação e manuseio.

O SEI começou a ser produzido pelo Ministério da Saúde a partir do dia 1ํ de julho de 2017 e, desde então, mais de 500 mil processos foram criados e, aproximadamente, 2 milhões de documentos foram produzidos até junho de 2018. No Distrito Sanitário Especial Indígena Médio Rio Purus, a plataforma digital passou a ser utilizada em outubro de 2017 e, desde então, contribui com a economia de materiais de expediente, há redução no tempo de trâmite dos processos, aumento na produtividade de servidores e demais colaboradores e melhoria no acesso de informações e gestão do conhecimento. Conforme Nascimento (2017, p. 12) "a gestão de documentos nas organizações pública atua como facilitador do acesso à informação, bem como aprimora os aspectos que propiciam a transparência, a fiscalização e o controle mais efetivos das atividades dos órgãos públicos". 
Neste contexto, Uchoa e Amaral (2013, p. 9) destacam os seguintes benefícios que podem ser almejados com a implementação do SEl:

- Diminuição de gastos financeiros e ambientais relacionados à impressão (impressoras, toner, papel, contratos de impressão);

- Diminuição de gastos operacionais associados à entrega e ao armazenamento de documentos e processos;

- Diminuição do tempo gasto na abertura, manipulação, localização e tramitação de documentos e processos;

- Redução de perdas, extravios e destruições indevidos de documentos e processos;

- Compartilhamento simultâneo de documentos e processos para fins de contribuição, acompanhamento da tramitação ou simples consulta;

- Suporte aos servidores em suas atividades diárias, com a disponibilização de modelos e orientações sobre como proceder em situações específicas;

- Transparência na publicidade de processos, tornando mais fácil o acompanhamento por servidores, agentes públicos em geral e o seu controle interno e pela sociedade;

- Maior performance na gestão do conhecimento e da possibilidade de melhoria de processos em razão da criação de uma plataforma única que permitirá a análise de fluxos de processos, sua comparação entre órgãos distintos e a melhoria baseada em experiências de sucesso;

- Aumento da previsão de definição, coleta e utilização direta e cruzada de dados e indicadores em razão da criação de um conjunto de bases de dados de mesma natureza.

Almeida (2016, p. 1) relata que "a implantação do SEI produz impactos positivos não só nas rotinas internas do órgão, mas também na interação com outros órgãos que fazem parte do Processo Eletrônico Nacional (PEN)". Comparado a outros softwares utilizados em alguns órgãos públicos, o SEI permite a busca e consulta a quaisquer processos ou documentos cadastrados, além do mais, a solução atende plenamente os requisitos determinados pela Lei de Acesso à Informação, uma vez que as regras 
são vinculadas de acordo com o tipo de processo, seja ele sigiloso, restrito ou público (NASCIMENTO, 2017). O SEl é um mecanismo de gestão que está em constante aprimoramento, e, assim, as experiências vividas nas mais diferentes organizações públicas são levadas em consideração no melhoramento da plataforma eletrônica, que é devidamente monitorada pelo Ministério da Economia e TRF4, sendo que, este último, é responsável por consolidar, testar, validar e só então distribuir aos demais órgãos utilizadores.

Ressalta-se que a medida adotada visa que todas os órgãos da Administração Pública possuam a mesma versão do software (SARAIVA, 2018). Fato é que há muito a melhorar quando se refere a implantação do SEI na Administração Pública federal, tendo em vista que centenas de órgãos utilizam o sistema. Destarte, é necessário que se mantenha o processo de aprimoramento contínuo desta plataforma digital, de modo que novas funcionalidades sejam incorporadas e subsidiem o desenvolvimento dos processos e documentos institucionais em âmbito geral (SARAIVA, 2018).

\subsection{ATIVIDADES DE GESTÃO POR MEIO DO SEI}

As atividades de gestão por meio de processos físicos são caracterizadas pela permanência contínua da utilização do papel como insumo primário para o desenvolvimento dos procedimentos administrativos, elevado tempo na tramitação processual, tendo em vista o trânsito físico dos documentos, além da dificuldade para acesso aos processos arquivados e prejuízo ao compartilhamento do conhecimento organizacional (BRASIL, 2016). Por sua vez, o SEI, enquanto mecanismo de gestão, proporciona, aos gestores, informações em tempo real, agilidade na elaboração de processos e documentos, altos índices de produtividade pelos servidores, redução do trâmite dos processos em até 99\%, melhoria de atendimento ao cidadão, melhoria na transparência e diminuição de 70\% no ambiente de armazenagem (BRASIL, op. cit.).

Em comparação ao desenvolvimento das atividades por processos físicos e eletrônicos, percebe-se um abismo gigantesco de eficiência na Gestão Pública. Primeiramente, pelo fato de os meios físicos demandarem altos custos contratuais com aquisição de papéis e serviços de postagem, aliados ao fato da demora na 
tramitação de documentos entre instituições ou, até mesmo, no ambiente interno do órgão, baixa produção por parte dos servidores e colaboradores que prestam serviços, perda de documentos, degradação ao meio ambiente e centralização das pessoas no ambiente interno para execução das atividades (BRASIL, op. cit.). Com o contínuo avanço da tecnologia da informação, as organizações passaram a utilizar os sistemas eletrônicos de informações para processarem, organizarem e controlarem o desenvolvimento dos processos de gestão e, consequentemente, a tomada de decisões com mais credibilidade.

Tão certo é que essas respectivas ferramentas modernizaram tanto o setor público quanto o privado e, hoje, são imprescindíveis nas tarefas realizadas diariamente (SILVA, 2015). Assim sendo, os sistemas eletrônicos de informações são essenciais para a disseminação do conhecimento. Entretanto, nenhum sistema é melhor do que as pessoas que irão operá-lo, o que ocasiona a necessidade constante de treinamento dos envolvidos e que e estes sejam otimistas acerca dos benefícios oriundos da utilização da plataforma eletrônica (BENETTI; MARÇAL, 2006). Portanto, os sistemas eletrônicos de informações são ferramentas necessárias para a boa gestão dos processos administrativos, usados pela Administração Pública, uma vez que os gestores podem acessar os processos de sua jurisdição de qualquer lugar, proporcionando maior economicidade do material, pois dispensa-se o uso de papéis e evita-se a celeridade dos processos, bastando, apenas, ter acesso a um terminal com internet.

\section{RESULTADOS E DISCUSSÕES}

\subsection{ASPECTOS DO SEI QUE FORAM ALCANÇADOS DURANTE A IMPLEMENTAÇÃO DO PROGRAMA}

Desde a criação da Secretaria Especial de Saúde Indígena, em 19 de outubro 2010, pelos Decretos № 7.335 e № 7.336, órgão ao qual o Distrito Sanitário Especial Indígena Médio Rio Purus é subordinado, observa-se que, entre os anos de 2012 à 2017, período esse que antecedeu a implementação do SEI, houve gastos, somente 
com aquisição de material de escritório, o montante de $\mathrm{R} \$ 358.601,43$ (trezentos e cinquenta e oito mil seiscentos e um reais e quarenta e três centavos), enquanto nos dois anos após a implantação os gastos com os mesmos materiais resultaram o montante de $R \$ 13.344,90$ (treze mil trezentos e quarenta e quatro reais e noventa centavos) para o atendimento das demandas internas da instituição, com vistas ao andamento dos processos. Para melhor exemplificar os gastos, tem-se a tabela 1, um demonstrativo da modalidade e seus respectivos valores antes da adesão do SEI pelo DSEI:

Tabela 1 - Despesas com aquisição de material de expediente - 2012 a 2017

\begin{tabular}{|c|c|c|c|c|}
\hline & & Licita ção & $\begin{array}{l}\text { Dispensa de } \\
\text { Licita ção }\end{array}$ & \\
\hline 2012 & $25038.000004 / 2012-33$ & $\begin{array}{l}\text { Dispensa de } \\
\text { Licitação }\end{array}$ & $03 / 2012$ & $\mathrm{R} \$ 6.220,00$ \\
\hline 2013 & $25038.000137 / 2013-91$ & $\begin{array}{l}\text { Dispensa de } \\
\text { Licitação }\end{array}$ & $02 / 2013$ & $\mathrm{R} \$ 7.878,90$ \\
\hline 2014 & $25038.000000 / 2014-14$ & $\begin{array}{l}\text { Dispensa de } \\
\text { Licitação }\end{array}$ & $02 / 2014$ & $\mathrm{R} \$ 7.757,00$ \\
\hline & $25038.000077 / 2014-97$ & $\begin{array}{l}\text { Pregão } \\
\text { Eletrônico }\end{array}$ & $11 / 2014$ & $\mathrm{R} \$ 313.983,03$ \\
\hline 2015 & $25038.000347 / 2015-41$ & $\begin{array}{l}\text { Dispensa de } \\
\text { Licitação }\end{array}$ & $06 / 2015$ & $\mathrm{R} \$ 7.150,00$ \\
\hline 2016 & $25038.000020 / 2016-50$ & $\begin{array}{l}\text { Dispensa de } \\
\text { Licitação }\end{array}$ & $01 / 2016$ & $\mathrm{R} \$ 7.715,00$ \\
\hline 2017 & & $\begin{array}{l}\text { Dispensa de } \\
\text { Licitação }\end{array}$ & $05 / 2017$ & $\mathrm{R} \$ 7.897,50$ \\
\hline \multicolumn{4}{|c|}{ Total } & RS $358.601,43$ \\
\hline
\end{tabular}

Fonte: Siasgnet - www.comprasgovernamentais.gov.br

Os dados apresentados na Tabela 1 representam os custos que a Administração Pública teve no período de 2012 a 2017, período antes da implantação do PEN, sendo que 0 ano de 2014 foi o de maior despesa, fato justificado pela alta demanda de impressões de cunho administrativo, formulários para as equipes multidisciplinares de saúde indígena - EMSI e capacitações de colaboradores e indígenas em geral. Cabe ressaltar que desde o dia 08 de outubro de 2017 todas as organizações públicas federais diretas, autárquicas e fundacionais estão obrigadas a fazerem uso do meio eletrônico para a realização do processo administrativo, em conformidade com o Art. 22, §1ํㅡ, da Lei oㅡ 8.539/2015. Por conseguinte, anos após foi publicada a Portaria do 
MPDG № 17, de 7 de fevereiro de 2018, revogada pela Portaria № 179, de 22 de abril de 2019, veda-se a despesa com a contratação, prorrogação ou substituição de softwares informatizados de controle e movimentação de processos administrativos eletrônicos diferentes dos disponibilizados pelo Ministério da Economia (SARAIVA, 2018).

Neste sentido, foi implantado o programa digital no Distrito Sanitário Especial Indígena Médio Rio Purus no ano 2018, e, com a implementação do sistema, observou-se uma redução das despesas, maior agilidade nos trâmites de documentos e processos institucionais, maior produtividade dos servidores, maior transparência e rapidez nos processos decisórios, dados esses comprovados pela tabela 2:

Tabela 2 - Despesas com aquisição de material de escritório - 2018 a 2019

\begin{tabular}{ccccc}
\hline Ano & Núm ero do Processo & $\begin{array}{c}\text { Modalidade } \\
\text { de Licitação }\end{array}$ & $\begin{array}{c}\text { No do Pregão } \\
\text { / Dispensa de } \\
\text { Licitação }\end{array}$ & Valor Total \\
\hline 2018 & - & - & - & - \\
2019 & $25038.000127 / 2019-41$ & $\begin{array}{c}\text { Dispensa de } \\
\text { Licitação }\end{array}$ & $04 / 2019$ & $\mathrm{R} \$ 13.344,90$ \\
Total & & RS 13.344,90
\end{tabular}

Fonte: Siasgnet - www.comprasgovernamentais.gov.br

Os dados da tabela 2 retratam a eficiência do SEI, auferindo-se que após um ano de implantação da plataforma digital, não houve, em 2018, compras realizadas para a aquisição de materiais de expediente. As despesas contraídas no exercício de 2019 deram-se em função da necessidade de alguns materiais para as equipes multidisciplinares de saúde indígena, como livros atas, canetas, lápis, envelopes, dentre outros, equipes essas que realizam atendimentos básicos de saúde dentro das aldeias e que não dispõem de meios eletrônicos para registrarem suas produções. Neste caso, a utilização do papel e demais itens ainda é imprescindível à na realização das atividades. Dos objetivos propostos na implementação do software no Distrito Sanitário Especial Indígena Médio Rio Purus, boa parte já foram alcançados, como, por exemplo: 
a) No exercício de 2018, não foi realizada nenhuma despesa com aquisição de materiais de expediente;

b) O contrato de locação de impressora, estimado no valor de $R \$ 111.000,00$ (cento e onze mil reais), não será renovado, em virtude do baixo índice de impressões atualmente realizado pela instituição;

c) O contrato firmado com a Empresa Brasileira de Correios e Telégrafos - ECT, com valor de $\mathrm{R} \$ 62.000,00$ (sessenta e dois mil reais) para serviços de postagem e malote foi rescindido em fevereiro de 2019 por falta de demanda, pois 80\% (sessenta por cento) dos profissionais administrativos atualmente em exercício na instituição já foram capacitados e operacionalizam o SEI em seus setores e somente os $20 \%$ de profissionais que trabalham nas Casas de Saúde do Índio - CASAI, por não disporem de acesso à internet para desenvolvimento dos processos dentro da plataforma eletrônica, ainda não foram capacitados para utilização do sistema.

Observa-se, portanto, que a implementação do SEI no Distrito Sanitário Especial Indígena Médio Rio Purus possibilitou maior agilidade no envio e recebimento de processos para a Consultoria Jurídica da União no Estado do Amazonas - CJU/AM, assim como, também, para a Secretaria Especial de Saúde Indígena em Brasília/DF e demais instituições parceiras do órgão. Nas tabelas 3 e 4 demonstrar-se-á o tempo gasto com a tramitação de processos e documentos antes e pós implantação do SEI nas duas principais organizações com as quais o DSEI se relaciona diariamente.

Tabela 3 - Tempo de envio e recebimento de processos e documentos, antes do SEI

\begin{tabular}{cccc}
\hline Destino & Órgão & Tempo de envio & $\begin{array}{c}\text { T empo de } \\
\text { Recebimento }\end{array}$ \\
\hline Manaus-AM & CJU/AM & De 07 a 12 dias & De 30 a 60 dias \\
Brasilia-AM & SESAI & De 20 a 30 dias & De 60 a 120 dias \\
\hline
\end{tabular}

Fonte: Serviço de Recursos Logísticos - SELOG / Distrito Sanitário Especial Indígena Médio Rio Purus 
A tabela 3 demonstra a onerosidade de tempo perdido em relação ao trâmite dos processos e documentos institucionais, o que reflete, diretamente, na produção dos servidores e colaboradores, além de afetar a aquisição e contratações de bens e serviços comuns que subsidiam as atividades de atendimento a comunidade indígena adstrita ao órgão. Contudo, após a implantação do SEl, percebe-se a agilidade e praticidade na tramitação dos processos, como podemos observa na tabela 4 , referente ao tempo de envio e recebimento de processos via digital:

Tabela 4 - Tempo de envio e recebimento de processos e documentos, pós implantação do SEI

\begin{tabular}{cclc}
\hline Destino & Órgão & Tempo de envio & $\begin{array}{c}\text { T empo de } \\
\text { Rec ebim ento }\end{array}$ \\
\hline Manaus-AM & CJU/AM & De 01 a 05 minutos & De 01 a 15 dias \\
Brasilia-AM & SESAI & De 01 a 05 minutos & De 01 a 30 dias \\
\hline
\end{tabular}

Fonte: Serviço de Recursos Logísticos - SELOG / Distrito Sanitário Especial Indígena Médio Rio Purus

Os dados apresentados na tabela 4 apontam para o oposto em relação à tabela 3, no que toca à implementação do $\mathrm{SEI}$, sendo que este propiciou maior agilidade na tramitação dos processos, reduzindo drasticamente o tempo de envio e recebimento dos mesmos, resultando em uma maior eficiência por parte do órgão nos procedimentos de aquisições e contratações diárias. Portanto, os dados apresentados nas tabelas retratam a eficiência que o SEI proporcionou na elaboração de documentos e processos tramitados diariamente, contribuindo com o aumento da produtividade nos procedimentos de aquisições e contratações de serviços necessários ao atendimento de toda clientela indígena adstrita ao Distrito Sanitário Especial Indígena Médio Rio Purus, bem como houve a padronização dos documentos da administração, otimizando-se o tempo de trabalho.

\section{CONSIDERAÇÕES FINAIS}

A implementação do SEI enquanto mecanismo de gestão para otimização dos processos administrativos no Distrito Sanitário Especial Indígena Médio Rio Purus 
trouxe muitos benefícios para a gestão e para a comunidade, uma vez que possibilitou maior agilidade no envio e recebimento dos processos para a Consultoria Jurídica da União no Estado do Amazonas - CJU/AM, bem como para a Secretaria Especial de Saúde Indígena em Brasília/DF e demais instituições parceiras. O tempo gasto com a tramitação de processos e documentos reduziu, de forma expressiva, os trâmites entre as principais entidades com as quais o DSEI se relaciona. Ao avaliar o desenvolvimento das atividades de gestão por meio de processos físicos, período anterior a implementação do programa e via SEI, percebeu-se a importância que o software exerce enquanto mecanismo de gestão para o Distrito Sanitário Especial Indígena Médio Rio Purus, conforme consta nas Tabelas 1, 2, 3 e 4. A implementação do programa fez com que os objetivos fossem alcançados.

Pode-se concluir que as principais vantagens fomentadas pela implementação do SEI são: portabilidade, acesso remoto, a redução de despesas com materiais de expediente, serviços de postagem podem ser feitos com uma maior eficácia, há uma maior produtividade dos servidores e colaboradores em geral, houve uma redução significativa tangente ao tempo de tramitação de documentos e processos organizacionais, ênfase na sustentabilidade, informações em tempo real para a tomada de decisões e, ainda, detectou-se a preservação do meio ambiente e apresenta como limitação a necessidade de acesso à internet. Por fim, ressalta-se a necessidade de implantação do SEI nas Casas de Saúde do Índio - CASAI de Lábrea/AM e Tapauá/AM, bem como nos polos base adstritos ao Distrito Sanitário Médio Rio Purus, tendo em vista a importância da plataforma digital nas sedes administrativas do órgão.

\section{REFERÊNCIAS}

ALMEIDA, C. P. de. Projeto de intervenção para implantação do sistema eletrônico de informações (SEI) no âmbito do Ministério do Desenvolvimento Social e Agrário - MDSA. Escola Nacional de Administração Pública (ENAP). 30 p. 2016. 
BENETTI, E. D.; MARÇAL, R. F. M. Sistema informatizado para controle e planejamento da manutenção em equipamentos que compõem a infraestrutura do sistema de informação de uma organização. In: XIII SIMPEP, 2006.

BRASIL. Ministério da Saúde. Secretaria Executiva. Programa Saúde Indígena: etnodesenvolvimento das sociedades indígenas/Ministério da Saúde, Secretaria Executiva. Brasília: Ministério da Saúde, 2001.

BRASIL. Ministério do Planejamento, Secretaria de Logística e Tecnologia da Informação Orçamento e Gestão (MPOG). O Processo Eletrônico Nacional e a solução que revolucionou a gestão dos processos administrativos governamentais. Escola Nacional de Administração Pública (ENAP), 15 p. 2016.

BRASIL. Ministério da Saúde. SecretariaExecutiva. Subsecretaria de Assuntos Administrativos. Manual do Sistema Eletrônico de Informações - SEI: Ministério da Saúde/ Ministério da Saúde, SecretariaExecutiva, Subsecretaria de Assuntos Administrativos. Brasília: Ministério da Saúde, 2018, 98 p.

CAPELLÃO, A. T. R. Sistema de Informações Gerenciais. Curitiba: Ibpex, 2008.

CASSARRO, A. C. Sistemas de informações para tomadas de decisões. $4^{a}$ ed. São Paulo: Cengage Learning, 2010.

JANNUZZI, C. A. S. C.; FALSARELLA, O. M.; SUGAHARA, C. R. Sistema de Informação: um entendimento conceitual para a sua aplicação nas organizações empresariais. Perspectivas em Ciência da Informação, v. 19, n. 4, p. 94-117, out./dez. 2014.

JANNUZZI, C. A. S. C.; TÁLAMO, M. de. F. G. M. A empresa e os sistemas humanos de informação: uma abordagem conceitual para a gestão da informação. Transinformação, v. 16, n. 2, p. 171-187, 2004.

LAUDON, K. C.; LAUDON, J. P. Gerenciamento de sistemas de informação. $3^{a}$ ed. Rio de Janeiro: Livros técnicos e científicos - LTC, 2001. 
LAUDON, K. C.; LAUDON, J. P. Sistemas de Informação. Rio de Janeiro: Livros técnicos e científicos - LTC, 1999.

NASCIMENTO, P. R. da. S. Impactos da implantação do sistema eletrônico de informação (SEI): Estudo de caso da Universidade de Brasília. 2017.138f. Dissertação (Mestrado em Economia) - Universidade de Brasília, Brasília, DF, 2017.

O' BRIEN, J A. Sistemas de Informação e as Decisões Gerenciais na Era da Internet. São Paulo: Saraiva, 2002.

SARAIVA, A. A implementação do SEI - Sistema Eletrônico de Informações. Escola Nacional de Administração Pública (ENAP), 11 p. 2018.

SILVA, L. B. da. Sistemas de informações em saúde como ferramenta para gestão do SUS. Saúde e Desenvolvimento, v. 8, n. 5, 2016.

TURBAN, E.; MCLEAN, E.; WETHERBE, J. Tecnologia da Informação para gestão. $3^{a}$ ed. Porto Alegre: Bookman, 2004.

UCHOA, C. E.; AMARAL, V. L. Processo Eletrônico Nacional: Uma solução universal de processo eletrônico. Brasília, 2013.

Enviado: Novembro, 2020.

Aprovado: Dezembro, 2020. 